\title{
Ferrera Balanquet, Raúl Moarquech (comp.) (2015). Andar erótico decolonial. El desprendimiento. Buenos Aires: Ediciones del Signo.
}

\author{
Celenis Rodríguez-Moreno
}

$\mathrm{D}$ esde que Aníbal Quijano acuñó la categoría "colonialidad del poder" a comienzos de los años noventa del siglo pasado, se han producido muchos trabajos que han ampliado y profundizado las temáticas que derivan de esta idea: colonialidad del saber, colonialidad del ser, biocolonialidad del poder, colonialidad de la democracia y, por supuesto, colonialidad de género. Esta última categoría ha resultado determinante para revisar las relaciones sociales y los regímenes corporales y de deseo, pre intrusión, más allá de las lógicas patriarcales y heterocéntricas occidentales, es este el eje de los trabajos "Género y colonialidad: en busca de claves de lectura y de un vocabulario estratégico descolonial" de la antropóloga argentina Rita Segato, y "Colonialidad y Género" de la filósofa argentina María Lugones. Vale decir que es en este trabajo donde Lugones va a llevar más lejos sus hipótesis, en las cuales niega la existencia del género y de un orden heteronormativo entre las comunidades precolombinas, para insistir en la idea de la imposición de un sistema moderno colonial de género que producirá los cuerpos y las subjetividades indígenas, y también negras, a (casi) imagen y semejanza de los varones y mujeres blancas heterosexuales. De esta manera, las feministas decoloniales abrieron un gran campo de debate que se ha ido enriqueciendo con nuevas discusiones, enfoques y temáticas, que exploran las prácticas y las ideas en torno a la sexualidad, las identidades de género, las estéticas corporales, el placer, las formas del deseo y los afectos desde "un locus de enunciación situado". Es en este gran debate donde se inscribe el libro Andar erótico decolonial, que con sus siete capítulos pretende sistematizar lo que se podría denominar como una nueva área de los estudios decoloniales: la colonialidad del deseo o la colonialidad del placer, términos que ya han sido utilizados por Víctor Manuel Rodríguez.

Andareróticodecolonial, compilado por Raúl Moarquech Ferrera Balanquet, inicia de una manera provocadora, con un corto prefacio de Walter Mignolo sobre el "desprendimiento", expresión que da nombre a la serie, pero que también explica los objetivos políticoepistémicos de crear conocimiento decolonial, ese que se desprende, se separa, o eso pretende, de los marcos de comprensión y explicación occidentales. En el caso de este volumen, se propone un desprendimiento con respecto a los saberes eurocentrados sobrela sexualidad y el erotismo, desprendimiento que supone "que ya conocemos lo suficiente de la colonialidad del poder como para largarnos a andary a ejercitar modos de/descoloniales de ser, de estar en el mundo, de hacer -el "andar es ya caminar la senda de la descolonialidad" (p. 12). 
La estructura del libro consta de siete capítulos. El primero, titulado "El futuro ya fue: una crítica a la idea del progreso en las narrativas de liberación sexo-genéricas y queer identitarias en Abya Yala" es de la autoría de la feminista descolonial afrocaribeña Yuderkys Espinosa Miñoso, quien hace una revisión sobre cómo se ha producido conocimiento sobre la sexualidad en América Latina de manera dependiente de los enfoques teóricos eurocéntricos - teoría queer, feminismo postestructuralista-, lo que implicó la marginalización de otras epistemes, de otros modos de comprender el afecto, el deseo y la sexualidad, pero también la reducción y homogeneización de las experiencias sexoafectivas locales y regionales a las etiquetas construidas a imagen y semejanza de la experiencia blanca europea. En este sentido, descubre la ontologización del sujeto de la disidencia sexual/blanco/burgués, del sujeto que hará estallar el heteropatriarcado, en un relato que parece decirnos que el progreso y la emancipación sólo son posibles a través de la occidentalización de la vida y la sexualidad.

Para poner en evidencia este ejercicio de colonialidad del saber, Espinosa revisa la bibliografía producida y traducida en Argentina, Chile, Brasil y México desde finales de la década de los noventa, años del giro postestructuralista y de la teoría queer en América Latina. La crítica abierta por Espinosa va acompañada por una invitación a construir una genealogía de las prácticas sexoafectivas y de los modos de sentipensar el cuerpo, los sentidos y los afectos que se resisten a los moldes eurocentrados. Esto es también lo que intentan hacer Raúl Moarquech Ferrera y Daniel Brittany Chávez en sus trabajos.

El ensayo de Ferrera, titulado "Navegar rutas decoloniales rumbo a relatos de origen karibeños", recoge la experiencia sentipensante del sujeto no sólo exiliado de la nación heteronormativa patriarcal socialista, sino también autoexiliado de las epistemes occidentales. La ruta que emprende va al encuentro de lo erótico decolonial: "Erótico decolonial no es sexualidad, ni la preferencia, pero la sexualidad y la preferencia están integradas al poder erótico decolonial, el cual está relacionado con el sentir, el pensar irracional y el hacer de todos los ámbitos de la expresión subjetiva y social, no sólo en el sentir y/o expresión sexual" (p. 47).

Para ello pone en diálogo los saberes y experiencias de las culturas taínas, mayas, incas y africanas instaladas en el Caribe, que no se limitan a lo que conocemos como sexualidad y género, sino que abarcan las cosmogonías, las prácticas de siembra, la vestimenta, las prácticas de cuidado y, por supuesto, el sentipensamiento de la comunidad. Ferrera Balanquet hace vislumbrar, entonces, una pulsión erótica ancestral difícil de reconocer con los instrumentos de análisis de la ciencia de Occidente.

Este texto es también el reflejo de la frustración de un activista y pensador de la disidencia sexual del "tercer mundo" con la teoría queer, a la que considera incapaz de autocrítica por su sesgo masculinista blanco eurocentrado, y a la que poco parecen interesarle las críticas planteadas por el feminismo y por los grupos racializados. Además, sostiene, a través de la teoría queer es imposible expresar las experiencias, el cuerpo, los sentidos y el imaginario erótico de las comunidades subalternizadas, ya que reduce la comprensión de lo erótico a la sexualidad individualizada y al realismo visual de occidente. Las rutas eróticas que propone Ferrera son las de un imaginario erótico decolonial, las del poder erótico que libera los cuerpos y sentires ininteligibles incluso para los autodenominados "monstruos"

Por su parte, el ensayo de Daniel Brittany Chávez "Devenir performerx: hacia una erótica soberana descolonial Niizh Manitog", con sus reflexiones sobre el performance nos introduce en el poder de una "erótica soberana" capaz de sanar los cuerpos de los dolores que causan las imposiciones coloniales en materia de género y sexualidad. Los cuerpos deben hacerse soberanos para rastrear la memoria ancestral de otros modos de sentir y saber, en los que no exista la censura o la autocensura para encarnar identidades múltiples o vivir sexualidades otras. El papel del performance consiste en servir de punto de partida o de llegada para la soberanía corporal, es decir, crea un espacio de libertad para imaginar y generar formas descolonizadas de sentir y explorar los cuerpos, pero para ello es necesario 
identificar y reconocer los elementos que colonizan nuestras existencias y conectar el placer y el goce no sólo con la sexualidad, sino con la capacidad profunda de sentir, tal como lo sostiene Audre Lorde con su idea de erotismo en "Uses of the erotic: the erotic as power" . El performance permitiría el desprendimiento de la norma colonial de género y sería el vehículo para expresar la pulsión erótica ancestral.

Resulta llamativo cómo este trabajo intenta pensar el performance como estrategia de descolonización, lo que parece riesgoso si tenemos en cuenta que su poderío deslumbra entre multitudes queer blancas cuyos privilegios les permiten transformaciones físicas que intervienen en la producción performativa de las identidades de género, lo que sin duda no ocurre cuando se trata de cuerpos marcados por la materialidad impuesta por el orden racial. Consciente de ello, el performance que piensa Chávez no se obsesiona con los cambios físicos, sino con la posibilidad de creación, de búsqueda de un espacio de libertad e imaginación donde concurra la memoria ancestral de lo erótico como horizonte de descolonización de los cuerpos.

La marginación de las epistemologías ancestrales sobre los cuerpos que han venido señalando los y las autoras de esta compilación fue posible por las sucesivas operaciones de corte y edición a que fueron sometidas las lenguas aborígenes, como bien señala Isaac Esaú Carrillo Can en su texto "Erotismo andróginx en la cosmovisión y lenguaje maya". Carrillo, autor de la novela U yóok 'otilo 'ob áak 'ab. Danzas de la noche, relata cómo a través de la expresión relacional in láak' ech, a láak' en de la cosmovisión y lengua mayas, que significa "ser el otro yo", logró construir la voz de la protagonista. Este ejercicio creativo lo motivó a buscar en diccionarios mayas expresiones y palabras que ponían en jaque la organización sexogenérica de la vida social impuesta por los colonizadores; de esta manera, encontró palabras como leti, ojel, paklam o etail, que hablan de androginia, de sexo entre varones, de sexo entre mujeres o de amistades sexualizadas, razón por la cual fueron sometidas a revisión y censura, y a una traducción que las aprisionaba en el esquema heteronormativo colonial, por lo que se redujo el erotismo cósmico de la lengua maya a los simples actos corpóreos que tanto escandalizaban a la Iglesia.

Lo interesante en el ejercicio de Carrillo es la reconstrucción, el trabajo de armar y ordenar los conceptos y las ideas que integraban las epistemologías borradas, casi aniquiladas, durante el proceso de imposición del sistema moderno colonial de género. Lo que pone en evidencia este escritor maya es una de las tantas formas como se llevó a cabo el epistemicidio de los pueblos ancestrales.

Por su parte, Sandra Abd'Allah-Álvarez, en "No somos tetas y nalgas solamente, feminidades disidente del hip hop cubano", explora la resignificación del lugar de las mujeres negras y pobres en la escena del hip hop de la isla, tradicionalmente asociadas con cualidades contradictorias, porque las describen como tiernas y amorosas, al tiempo que las señalan como putas e hipersexuales. Estas ideas se han ido complejizando debido al trabajo de artistas como la poeta Afibola Sifunola, la cantante Magia López y las Krudas Cubensi, quienes escriben y cantan sus líricas sobre las relaciones lésbicas, los embarazos adolescentes, el aborto, los cuerpos, el poliamor, el placer, el clítoris, la belleza y la experiencia de migración. Las letras, las rimas, el flow y el performance en escena forman una mezcla explosiva capaz de desestabilizar los imaginarios ligados a las jerarquías de género, raza, clase y sexualidad que ordenan la vida cotidiana.

"No somos tetas y nalgas solamente, feminidades disidentes del hip hop cubano" es un texto con planteamientos menos preocupados por las limitaciones epistémicas de la teoría queer, del feminismo y de los estudios de la sexualidad para comprender las experiencias corporales, eróticas y sexoafectivas que ocurren en contextos marcados por una historia de colonización. De hecho, para la autora es posible construir estrategias de descolonización con las herramientas de dichos marcos teóricos; sólo bastaría con una apropiación creativa por parte del sujeto/sujeta colonizada.

Víctor Manuel Rodríguez, con su trabajo "El guesa errante: éticas y estéticas trash/malandras/ delincuentes/desobedientes para mundos queer y 
decoloniales", nos traslada al universo creativo del artista brasileño Hélio Oiticica (1937-1980), lugar de subjetividades queer decoloniales donde se comparten no sólo los placeres perversos, sino también las experiencias migratorias, las drogas, la ética de la calle y, por supuesto, la solidaridad y el afecto. Sus quasi cinemas cuestionan las representaciones sobre las sexualidades marginales latinoamericanas producidas en contextos hegemónicos mediante la apropiación y repetición de los estereotipos queer latinos, y explora la configuración de la condición colonial latinoamericana. Para Rodríguez, en Eroiticica se pueden descubrir formas de articular las estrategias subversivas queer con formas de resistencia decolonial, como él mismo afirma: "Busco entonces tanto decolonizar la teoría queer, como queering o 'mariquear' los estudios decoloniales" (p. 118).

Tal vez, de los siete capítulos que componen este libro éste sea el más queer. El tema seleccionado, una producción artística marginal/underground, la referencia a los tropos y el problema de la representación son elementos recurrentes en este estilo de escritura y análisis. No obstante, el autor se esfuerza por realizar un abordaje decolonial que muchas veces se reduce a la mirada interseccional acumulativa de opresiones que da a la obra de Oiticica. A pesar de esto, es muy interesante la idea de utilizar las estrategias queer como un desestabilizador de las subjetividades sexuales moderno-coloniales, en la medida en que actúan contra los procesos de naturalización y los esencialismos propios de los disciplinamientos sexuales modernos.

El escrito de Pedro DiPietro "Andar de costado: racialización, sexualidad y la descolonización del mundo travesti en Buenos Aires" comprende un estudio de las prácticas de resistencia travesti frente a la necesidad de adopción de identidades sexuales modernas/blancas/eurocentradas — gay, lesbianas, transgénero, intersexual, transexual-, en un contexto de reconocimiento de derechos LGBT: matrimonio igualitario y la Ley de Identidad de Género. En ello juega un papel determinante su condición de migrantes de color, provenientes de regiones con un gran número de población indígena como Jujuy y Salta, que se ubican en los márgenes sociales y raciales de la ciudad de Buenos
Aires (quilomberas). Su estética hipersexual/arrabalera/ racializada inspirada en las mulatonas, sus estrategias habitacionales colectivas y la ocupación indecorosa del espacio público, las convierten en una disidencia no sólo para el público heteronacional, sino también para los contrapúblicos homonacionalistas.

Lo que se puede observar, entonces, es que los públicos y los contrapúblicos que nos presenta DiPietro aparecen superados por la irrupción de un sujetx travesti oscuro que incomoda a los "normales", pero también a los monstruos blancos. Esto último se debería, en primer lugar, a que los movimientos socio-sexuales (Argentina) mantienen una dependencia epistémica con respecto a la producción intelectual de los estudios de la sexualidad y queer blanca producidos en el norte, $y$, en segundo lugar, a que esto los ha llevado a identificar como el sujeto paradigmático de su lucha a un sujeto gay/blanco/de clase media, lo que al final se traduce en una agenda excluyente incapaz de comprender unas experiencias locales que desafían la sexualidad "diversa" blanca urbana.

\section{Un libro, dos rutas decoloniales}

Después de leer cada uno de los textos que compone este libro la sensación que queda es la de estar ante dos propuestas decoloniales diferentes para abordar la sexualidad, el cuerpo, el erotismo y el género. La primera propuesta, integrada por los trabajos de Yuderkys Espinosa, Raúl Ferrara, Daniel Brittany Chávez e Isaac Carrillo, sobresale por el esfuerzo epistemológico para superar el marco teórico occidental, que agudamente critica Espinosa apenas empezando el libro, de ahí que el uso de las categorías "género" o "sexualidad" sea menor para la construcción de argumentos, mientras se privilegian ideas como la de erotismo de Audre Lorde, erótica soberana de QwoLi Driskill o leti, de la cosmovisión maya, que aportan otro modo de entender el placer y la corporalidad, uno que supera lo individual y se conecta con la comunidad y el cosmos. Eso contribuye a que la escritura fluya más allá de cierto esquematismo que impone la formula interseccional. 
La otra ruta, la de Abd'Allah-Álvarez, Rodríguez Sarmiento y DiPietro, mantiene las referencias teóricas del feminismo y la teoría queer sin entrar en cuestionamientos epistémicos; de hecho, Rodríguez manifiesta que hay que buscar puntos de encuentro entre las estrategias queer y las decoloniales en aras de desmantelar el régimen sexual moderno. Sin embargo, apela a la interseccionalidad en el análisis ya sea de las mujeres negras, pobres y lesbianas que irrumpen en el hip hop cubano, de las travestis empobrecidas que con su estética racializada habitan las calles de Buenos Aires, o de los delincuentes/drogadictos, desviados sexuales migrantes del sur que habitan el mundo-abrigo neoyorkino de Oiticica.

Sin duda Andar erótico decolonial es un libro de gran riqueza que va a generar debates políticos y epistemológicos que complejizarán aún más el intento de comprender los efectos de la colonialidad del poder en nuestros cuerpos, nuestros deseos y nuestros afectos. Construir, producir conocimiento en clave decolonial sobre el placer, la sexualidad, los sentidos y el cuerpo, era urgente porque este campo es tal vez el más dominado por el saber hegemónico blanco liberal que, además, está marcando el rumbo de las agendas de la disidencia sexual en Abya Yala. No hay colectivo u organización feminista, obrera, estudiantil, de izquierda, comunitaria e incluso indígena que no construya el problema de la disidencia sexual con marcos teórico-políticos eurocéntricos. De esta manera, el impacto de esta compilación sería doble, ya que inaugura una nueva área dentro de los estudios decoloniales, pero también ofrece un nuevo horizonte político en las luchas del movimiento sociosexual en Abya Yala.

Por otra parte, para quienes han venido leyendo y estudiando a las feministas decoloniales este libro es una buena oportunidad para profundizar en los primeros debates de María Lugones y Rita Segato sobre la universalidad y transhistoricidad del sistema sexo/ género y la heterosexualidad, ya que en algunos de los textos se exploran las formas de expresión del placer y las cargas simbólicas y materiales que las culturas precolombinas asignaban sobre los cuerpos.

Otro aspecto para resaltar en el libro es que se arriesga a trazar una ruta de lo ancestral hasta los espacios urbanos, cuestión que siempre ha implicado dificultades para muchos autores decoloniales que, si bien son capaces de construir genealogías sobre los saberes y prácticas ancestrales africanas e indígenas, pocas veces las logran conectar y rastrear en las particulares formas que toman éstas en los contexto urbanos.

Por último, pero no menos importante, este libro ofrece más pistas para seguir armando ese complejo rompecabezas que es el sujeto colonial. Fanon, Cesaire, y más recientemente Spivak y Bhabha, han indagado sobre cómo tal sujeto se veía a sí mismo - la pregunta sobre quién soy - y su lugar en la sociedad, pero siempre desde una mirada generizada y heterocéntrica. Esas mismas preocupaciones recorren todo el libro, pero sus respuestas son múltiples y algunas inimaginadas, por lo que se podría decir que este trabajo supone otro giro, un "giro erótico decolonial". 